\title{
HISTÓRIA ORAL, VELHICE E O TEMPO PRESENTE: O CONTEXTO DO PATRIMÔNIO CULTURAL RURAL PAULISTA
}

\author{
Lívia Morais Garcia Lima \\ Centro Universitário Salesiano de São Paulo - UNISAL \\ livia.lima@am.unisal.br
}

\begin{abstract}
RESUMO
Este artigo tem por objetivo analisar e refletir sobre a contribuição da história oral nos estudos sobre o patrimônio e as ações de educação patrimonial em fazendas históricas paulistas. As questões aqui problematizadas fazem parte de uma pesquisa recentemente concluída, onde o patrimônio é explorado como espaço educacional dentro de uma visão da educação não formal no contexto rural, voltado para o público idoso, de formações educacionais e classes sociais diversas. A pesquisa sobre o patrimônio cultural rural paulista se torna um trabalho sobre a utilização dos bens culturais como fonte de lazer e turismo, possibilitando um exercício de sensibilização para a valorização dos espaços rurais, a partir da análise das representações dos sujeitos e seus papéis e do imaginário rural.
\end{abstract}

Palavras-chave: Velhice. História oral. Patrimônio.

\section{ORAL HISTORY, OLD AGE AND THE PRESENT TIME: THE CONTEXT OF RURAL SÃO PAULO CULTURAL HERITAGE}

\begin{abstract}
This article aims to analyze and reflect on the contribution of oral history in studies on equity shares and equity in education paulistas historic farms. Problematic issues here are part of a recently completed research, where the heritage is explored as an educational tourist space within a vision of non-formal education in the rural setting, facing the elderly public, educational backgrounds and different social classes. Research on the São Paulo countryside cultural heritage becomes a paper on the use of cultural property as a source of recreation and tourism, allowing an exercise in awareness of the value of rural areas, by analyzing the subjects' representations and their roles, the rural.
\end{abstract}

Keywords: Old age. Oral history. Heritage.

\section{HISTORIA ORAL, VEJEZ Y EL TIEMPO PRESENTE: EL CONTEXTO DEL PATRIMONIO CULTURAL RURAL PAULISTA}

\section{RESUMEN}

Este artículo tiene por objetivo analizar y reflexionar sobre la contribución de la historia oral en los estudios sobre el patrimonio y las acciones de educación patrimonial en haciendas históricas paulistas. Las cuestiones aquí problemáticas forman parte de una investigación recientemente concluida, donde el patrimonio es explotado como espacio educativo dentro de una visión de la educación no formal en el contexto rural, orientado hacia el público anciano, de formaciones educativas y clases sociales diversas. La investigación sobre el patrimonio cultural rural paulista se vuelve un trabajo sobre la utilización de los bienes culturales como 
fuente de ocio y turismo, posibilitando un ejercicio de sensibilización para la valorización de los espacios rurales, a partir del análisis de las representaciones de los sujetos y sus papeles y imaginario rural.

Palabras clave: Vejez. Historia oral. Patrimonio.

\section{L'HISTOIRE ORALE, LA VIEILLESSE ET LE PRESENT: LE CONTEXTE DU PATRIMOINE CULTUREL DE SÃO PAULO RURAL}

\section{RÉSUMÉ}

Cet article a pour but d'analyser et de réfléchir sur la contribution de l'histoire orale dans les études sur les actions d'éducation au patrimoine et au patrimoine dans les fermes historiques de. Les questions abordées ici font partie d'une recherche récemment achevée, où le patrimoine est exploré en tant qu'espace éducatif dans le cadre d'une vision de l'éducation non formelle en milieu rural destinée aux personnes âgées, aux formations et aux diverses classes sociales. La recherche sur le patrimoine culturel rural de São Paulo devient un travail sur l'utilisation des biens culturels comme source de loisirs et de tourisme, permettant un exercice de sensibilisation à la valorisation des espaces ruraux, basé sur l'analyse des représentations des sujets et de leurs rôles et l'imagerie rurale.

Mots-clés: Vieillesse. Histoire orale. Patrimoine.

\section{INTRODUÇÃO}

Este artigo tem por objetivo refletir sobre a contribuição da história oral nos estudos sobre o patrimônio e as ações de educação patrimonial em fazendas históricas paulistas. Na pesquisa, o patrimônio foi explorado como espaço educacional dentro de uma visão de educação patrimonial não formal no contexto rural, através de um turismo cultural em espaço rural que explique e contextualize a relação urbano/rural para os velhos que visitam as fazendas.

Tem-se observado que a cidade, independente de sua localização ou de seu tamanho, constrói-se pela acumulação de imagens múltiplas e variadas, reais e imaginadas, que atraem e criam o desejo de experimentar o seu charme, de penetrar e de descobrir os seus mistérios. Este poder de atração da cidade predispõe ao turismo. (ALMEIDA, 2011, p. 11).

Optei por assumir o termo velho ou idoso pelo fato destas categorias delimitarem com maior clareza as representações pelas as quais a velhice vem passando, enquanto o tratamento como "terceira idade", "melhor idade", "idade de ouro", "idade legal”, dentre outras, considero que são subterfúgios semânticos, palavras aprazíveis, tendo o propósito de encobrir um debate mais importante, que é a função social da velhice na nossa sociedade, em que o velho é alvo do mercado consumidor crescente, como por exemplo, o mercado turístico. 
O uso da designação "terceira idade" ou "melhor idade" ao invés de velhice vêm provocar um novo sentido que seria o sentido da não velhice, negando o sentido histórico da velhice como declínio, incapacidade, fragilidade e como fase de resignação às perdas da beleza e da capacidade físico-cognitiva. Essa nova sensibilidade considera a juventude como um valor dissociado à categoria etária, que deve ser preservado na vida das pessoas envelhecidas. (OLIVEIRA, 2009, p. 37).

Também sobre a concepção de velhice ativa atrelada à ideia de "terceira idade", Debert (1999) enfatiza o quanto essa expressão e os movimentos que se organizam em torno dela indicam mudanças radicais na forma como o envelhecimento é visto, deixando de ser compreendido como decadência física, perda de papéis sociais e retraimento. A autora cita como exemplo o grande número de programas para a "terceira idade" no Brasil, como os grupos de convivência, as escolas abertas e as universidades. Dessa forma, justifico ao assumir o termo idoso ou velho no presente artigo.

O espaço empírico da pesquisa foi o das fazendas históricas paulistas, selecionadas pelo projeto em Políticas Públicas em andamento denominado: "Patrimônio Cultural Rural Paulista: espaço privilegiado para pesquisa, educação e turismo" (Oitava Chamada para o Programa de Pesquisa em Políticas Públicas - PPPP). O projeto foi financiado pela Fundação de Amparo à Pesquisa do Estado de São Paulo - FAPESP, em parceria com o Centro de Memória UNICAMP, no período de 2008 a 2014, ao qual a pesquisa esteve vinculada.

O projeto PPPP/FAPESP reuniu dezoito propriedades em regiões significativas do Estado de São Paulo, sendo essas definidas pelos núcleos regionais compostos pelas cidades de Campinas, Limeira-Rio Claro, São Carlos-Araraquara, Itu, Mococa-Casa Branca e Vale do Paraíba. A Associação das Fazendas Históricas Paulistas atualmente é uma OSCIP (Organização da Sociedade Civil de Interesse Público) responsável por reunir essas propriedades históricas dos séculos XVIII, XIX, e início do século XX que trabalham com turismo no espaço rural. O projeto teve como objetivo principal disponibilizar um conjunto de instrumentos e de metodologias de gestão, de conservação e de difusão para os responsáveis por esse patrimônio cultural rural, tanto os proprietários quanto as respectivas instâncias públicas pertinentes à área da cultura, da educação e do turismo.

Segundo o coordenador do projeto, Tognon (2007), o Patrimônio Cultural Rural pode ser definido como o conjunto de registros materiais e imateriais decorrentes das práticas, dos costumes e das iniciativas produtivas que se estabelecem, histórica e territorialmente, na área rural.

As propriedades pesquisadas surgiram em decorrência da ocupação da região central paulista nos séculos XVIII e XIX, dada a grande diversidade de bens que formam o seu patrimônio histórico, cultural e natural. Essa diversidade de bens culturais se, por um lado, 
representa uma grande potencialidade para as atividades de pesquisa e para as ações de políticas públicas; por outro, apresenta permanentemente desafios no estabelecimento de procedimentos metodológicos que permitem a descoberta, a identificação, a caracterização, a análise e a descrição desses bens. Marins (2013) completa a ideia da importância dos estudos do meio rural paulista afirmando:

\begin{abstract}
Se hoje compreendermos as manifestações da arquitetura rural antes como suportes de memórias sociais e como documentos históricos sobre a vida social e material das populações brasileiras - e não apenas como monumentos que celebram uma visão cristalizada e excludente da sociedade brasileira baseada no cânone nacional -, a proteção de edificações e agenciamentos espaciais constitui imenso desafio às políticas de preservação do patrimônio cultural, especialmente no caso paulista. (MARINS, 2013, p. 164).
\end{abstract}

O autor ainda nos chama a atenção para que o atual território paulista abriga exemplares significativos de testemunhos arquitetônicos das culturas do trigo quinhentista e seiscentista, da produção de açúcar difundida durante a segunda metade do século XVIII, das fazendas de criações, da gigantesca vaga cafeicultora, das culturas de abastecimento e de ocorrências mais pontuais, como o algodão e a produção leiteira, muitas vezes ampliada e adaptada no tempo, por culturas que se sucederam.

O pesquisador responsável pelo PPPP/FAPESP, Tognon (2007), ainda ressalta que tal Patrimônio Cultural Rural possui um perfil múltiplo, em escalas e tipologias, que contemplam não só as fazendas históricas e os complexos produtivos antigos, mas também usinas e barragens para a implementação das pioneiras redes de produção e distribuição de energia elétrica do campo e da cidade, pontes, diques, ferrovias, enfim, registros edificados no território agrário que se somam aos acervos artísticos, bibliotecas, arquivos, equipamentos e máquinas, festas e arte popular, hábitos, costumes, crenças e modos de fazer.

Tognon (2003, p.163) complementa a ideia conceituando "os bens culturais como sendo os mais importantes resultados históricos da cultura humana na constituição do seu território". Tal tema para o autor ganha, a cada dia, espaço nas políticas públicas e que aos poucos se estende pelo Brasil e se associa a programas de estímulos a polos turísticos.

Pode-se perceber a amplitude que a atividade turística possui e que, ela remete a uma série de tipologias de turismo. E a tipologia de turismo que dialoga com o patrimônio cultural se refere justamente ao turismo cultural, que estaria relacionado a todo turismo cujo principal atrativo não seja a natureza, mas algum aspecto da cultura humana. (BARRETTO, 2001, p. 57).

Para dar conta dos objetivos propostos pelo artigo, foi realizada uma comparação entre três fazendas históricas paulistas, cujas atividades educacionais e turísticas se apresentam diversificadas, segundo três tipos de propriedades já diagnosticados: 
1- Visita - dia ou excursionismo: Propriedades que recebem visitas diárias de grupos ou famílias vindas de cidades próximas ou mesmo da capital ou grupos de turistas que estão realizando visitas em outras fazendas próximas. A fazenda disponibiliza almoço e/ou café no final da tarde para os visitantes. (Exemplo: Fazenda Quilombo, Limeira - SP.)

2- Turismo de Habitação: Propriedades que praticam o "turismo de habitação", isto é, recebem os turistas na própria casa-sede acomodados em quartos livres (suítes ou com banheiro partilhado). As refeições são feitas com os membros da família do proprietário e os hóspedes podem acompanhar a realização de todas as atividades agropecuárias cotidianas. Há assim uma proximidade com a família do proprietário e a curiosidade dos hóspedes (principalmente daqueles estrangeiros) é constantemente suprida com esclarecimentos e exemplos concretos. Tais propriedades costumam receber também visitas diárias de grupos ou famílias vindas de cidades próximas ou mesmo da capital. (Exemplo: Fazenda Mandaguahy, Jaú - SP e Fazenda Chácara do Rosário, Itu - SP, Fazenda Santo Antônio da Água Limpa, Mococa - SP).

3- Hotel-Fazenda: Propriedades que já possuem uma infraestrutura diversificada e sofisticada para receber os turistas se caracterizando como Hotéis-Fazenda. Possuem estruturas para o lazer (piscina, cocheiras e plantel de animais preparados para cavalgadas, quadras esportivas, passeios a pé guiados, etc.). Recebem hóspedes de classe média alta da capital e de cidades próximas, entre eles muitos estrangeiros. Recebem escolas que trabalham com educação patrimonial ou turistas no sistema day-use. (Exemplo: Fazenda Capoava, Itú - SP e Fazenda Bela Vista, Dourado - SP) (LIMA, 2010, p. 56).

Das dezoito fazendas históricas envolvidas no projeto, três foram selecionadas levandose em conta o desenvolvimento de atividades de educação patrimonial nas mesmas e sua localização em espaços centrais do estado de São Paulo:

- Fazenda Quilombo: localizada no município de Limeira - SP: foi a primeira propriedade selecionada pela pesquisa realizando o excursionismo ou a visita-dia ${ }^{1}$. Possui diversidade de culturas, sendo elas: café, bovinocultura de corte, criação de cavalos, produção de feno para comercialização, cultura de frutas tropicais e mais recentemente o turismo. Bortolucci (2013) ainda afirma que o nome da nova propriedade decorre da existência de esconderijos de escravos, facilitada pela topografia acidentada da região. Trata-se de uma propriedade que vem se mantendo na mesma família por várias gerações.

\footnotetext{
${ }^{1}$ De acordo com a duração, o turismo pode ser excursionista ou visita-dia, viagem que dura menos de 24 horas. (BARRETTO, 2001, p. 19)
} 
Além da atenção a estas culturas é foco constante dos proprietários a preservação do patrimônio histórico, para que o mesmo possa ser contemplado por visitantes que buscam relembrar o passado e compreender a importância da atuação de suas famílias no processo de desenvolvimento da lavoura cafeeira na região. Estudantes e pesquisadores têm na fazenda uma fonte de informação e proximidade para análises in loco. A fazenda constitui-se também em um atrativo para todas as pessoas interessadas em conhecer a história do ciclo do café numa propriedade centenária e ainda em pleno funcionamento o que pode ser feito em visitas dia, denominadas excursionismo

- Fazenda Santo Antônio da Água Limpa: localizada no município de Mococa - SP: foi a segunda propriedade selecionada pela pesquisa realizando o turismo de habitação ${ }^{2}$. Apesar de receber poucos turistas ao longo do ano, a propriedade é uma das poucas a realizarem esse tipo de turismo.

Situada a 20 quilômetros da cidade de Mococa no Estado de São Paulo, a fazenda tem 444 hectares. Em 1996, foi definitivamente implantada a Agricultura da 'Grande Natureza', nas palavras do proprietário João, sem o uso de fertilizantes químicos ou orgânicos e agrotóxicos, usando unicamente a energia do solo, da água e do sol. Tal implementação provocou uma verdadeira 'revolução na vida do solo e do ar', segundo o proprietário, causando um reflexo direto no sabor e aroma dos frutos, reflexos este que vem melhorando ano após ano, modificando o comportamento não só do solo, da água, do ar, da flora e da fauna, mas principalmente do homem. A fazenda oferece passeios pela propriedade, piscina com água de mina, cachoeira, degustação de café, aula de culinária, cavalgadas, contato com projetos sociais e de preservação da natureza.

- Fazenda Bela Vista: localizada no município de Dourado - SP: A propriedade possui pouca terra cultivável, sendo que, dos 130 alqueires de terra, boa parte é de mata nativa. Desde 1951, Pedro Luis de Aguiar, 80 anos, mais conhecido como Pedroca, é proprietário da Fazenda Bela Vista. Por estar catalogado no The Long Rider's Guild, o foco da propriedade é a criação de cavalos para a realização das cavalgadas com os turistas.

Com a realização do trabalho de campo na presente fazenda, constata-se que quem está na administração turística da propriedade é a filha do Pedroca, conhecida por Tucha. Dessa

\footnotetext{
2 A expressão "turismo de habitação" designa as modalidades de hospedagem em zonas rurais, orientadas para a exploração dos seus recursos naturais e culturais. Diferentemente do turismo convencional ou de massas, o turismo de habitação tende a ser um turismo localmente controlado, de caráter familiar, de pequena escala e em harmonia com o ambiente físico, social e cultural das comunidades de acolhimento, no qual o cliente é acomodado na casa do anfitrião (SILVA, 2007, p. 35).
} 
maneira, foi realizada uma entrevista com a proprietária, o que possibilitou a complementação de informações sobre o local.

A escolha da área central do Estado justifica-se pela concentração de fazendas históricas disponíveis e sensíveis à proposta, além de ser uma região que foi constituída, segundo o relatório de pesquisa do projeto "Fazendas"”, por meio de fazendas de café, de relações econômicas e sociais que deram origem a muitas das práticas culturais paulistas, tornando-se, portanto, representativa da integração da cultura caipira aos novos modos de vida trazidos pelo migrante (nacional ou internacional).

A outra face da discussão que esta pesquisa propõe é a da educação não formal, que assim pode ser definida:

A educação não formal, por poder lidar com outra lógica espaço-temporal, por não necessitar se submeter a um currículo definido a priori, por dar espaço para receber temas, assuntos, variedades que interessam ou sejam válidos para um público específico naquele determinado momento e que esteja participando de propostas, programas ou projetos nesse campo, faz com que cada trabalho e experimentação sejam únicos. E, por envolver profissionais e frequentadores que podem exercitar e experimentar outro papel social, que não o representado na escola formal (como professores e alunos), contribui com uma maneira de lidar com o cotidiano, com os saberes, com a natureza e com a coletividade. (SIMSON; PARK; FERNANDES, 2007, p. 13).

Sobre a cidade como espaço de educação não formal e potencialmente educadora, a autora Fernandes (2007), nos apresenta a ideia envolvendo equipamentos e instituições sociais, artísticas, culturais e de lazer e espaços públicos disponíveis no espectro da cidade, contribuindo dessa forma para a discussão e reflexão de um universo ampliado de práticas educativas que acontecem fora das instituições escolares e para diferentes grupos etários.

Desse modo, centros cívicos, zoológicos, bibliotecas, centros culturais e recreativos, museus, praças, parques, shoppings, monumentos, arquitetura, escolas de samba, movimentos populares e de rua ligados a música, a dança, as artes... Podem ser espaços ou locais de promoção e geração de educação para públicos de diferentes idades, grupos sociais, etnias etc. (FERNANDES, 2007, p. 3-4).

Entendendo que a educação lança mão da cultura, das artes, dos movimentos populares etc., com seus repertórios de saberes elaborados ao longo do tempo e que provocam aprendizagens, Graziano (2016) em sua tese de doutorado, propõe o termo município educador, abrangendo tanto as experiências formativas da cidade como do campo, focando, especialmente, o meio ambiente, o turismo e o patrimônio.

\footnotetext{
${ }^{3}$ Projeto aprovado no Programa Auxílio à Pesquisa - Regular - Chamada 09/2011 de Propostas FAPESPSEC/Condephaat: inventários de identificação, análise e seleção do Patrimônio Cultural Paulista, desmembrado em dois processos.
} 
Pude perceber então, que o patrimônio é explorado como espaço turístico dentro do campo da educação não formal no contexto rural paulista, envolvendo os patrimônios materiais e imateriais, para adultos e idosos, de diferentes formações educacionais e de classes sociais diversas.

Outro ponto de interface da necessidade de pesquisa foi notar que existem poucos estudos sobre a arquitetura rural e a preservação do patrimônio material e imaterial nesse espaço, principalmente quando nos referimos ao estado de São Paulo.

\begin{abstract}
Os tombamentos efetivados pelo IPHAN em alguns dos estados mais populosos do país demonstram claramente a fragilidade da proteção de bens representativos da arquitetura rural, senão um perfil quase excludente. [...]. Os espaços urbanos foram largamente privilegiados na preservação do patrimônio edificado, implementada pelo IPHAN, tanto quanto foram o período colonial, a arquitetura de expressão erudita, a escala monumental e as heranças portuguesas. (MARINS, 2013, p. 163).
\end{abstract}

O autor ainda ressalta que a prioridade na nomeação do patrimônio urbano face ao rural pode ser também associada ao perfil político do Estado Novo que, "evitando o tombamento das fazendas, não prestigiou os espaços rurais, nem a memória das elites agrárias, abaladas pelo regime Vargas" (MARINS, 2013, p. 163).

Também tomo como justificativa a originalidade da presente pesquisa, que incorporou pesquisas bibliográficas desenvolvidas até o momento, construindo para uma percepção direta das práticas educativas dos educadores no Brasil, notando-se uma carência de produções reflexivas nacionais, do ponto de vista do campo da educação não formal e ligadas ao campo do turismo e do patrimônio.

Assim, salienta-se a possibilidade do desenvolvimento de uma educação não formal, não estando restrita ao espaço urbano, e que se desenvolve em espaço rural possibilitando a compreensão por parte dos educandos do contexto agrário cafeeiro paulista e do patrimônio material e imaterial por ele produzido.

Nessa perspectiva, acredito na educação patrimonial, não apenas como uma metodologia, mas como um recurso prático dentro do campo da educação não formal, como um caminho que nos leva a valorização do indivíduo, de sua trajetória histórica e à descoberta de seu contexto cultural com caráter sedutor e envolvente, para serem seguidas voluntariamente pelo visitante/turista.

Mediante a pesquisa de campo realizada e através da análise das entrevistas, propôsse mostrar a intersecção da memória com a vida social. A opção pela metodologia da história oral contribuiu para a construção do corpus da pesquisa, porque tratou a entrevista com os 
participantes como um momento de troca entre o pesquisador e o pesquisado, permitindo assim novas reflexões sobre o imaginário e o espaço rural paulista.

\title{
HISTÓRIA ORAL E PATRIMÔNIO
}

\begin{abstract}
"O que é história oral? É um método? Uma disciplina? Um tema novo? Na minha opinião, é uma abordagem muito mais ampla: é a interpretação da história, das sociedades e das culturas por meio da escuta e do registro da história de vida das pessoas. E a habilidade fundamental na história oral é aprender a escutar." (THOMPSON, 2006, p. 12).
\end{abstract}

Davis (2003) trata o momento da entrevista como um evento interativo, uma performance que envolve as atividades de ambos: o entrevistador e o entrevistado, permitindo compreender a entrevista como uma construção reflexiva.

\begin{abstract}
Uma entrevista é uma troca entre dois sujeitos: literalmente uma visão mútua. Uma parte não pode realmente ver a outra a menos que a outra possa vê-lo ou vê-la em troca. Os dois sujeitos, interatuando, não podem agir juntos a menos que alguma espécie de mutualidade seja estabelecida. (PORTELLI, p.9, 1997).
\end{abstract}

O autor ressalta que o pesquisador de campo tem um objetivo amparado em igualdade, o que não pode ser desejada no fazer, mas como condição para uma comunicação menos distorcida e um conjunto de informações menos tendenciosas. Portelli (1997, p. 10) ainda afirma que "a entrevista levanta em ambas as partes uma consciência da necessidade por mais igualdade a fim de alcançar maior abertura nas comunicações".

Assim, para se discutir a História Oral como um procedimento de pesquisa, faz-se necessário inicialmente "tornar claro o significado atribuído à pesquisa, vista como forma de conhecer a realidade" (LANG, p. 91, 2001). Dessa forma, a autora defende a ideia de que:

\footnotetext{
A História Oral constitui uma metodologia qualitativa de pesquisa voltada para o conhecimento do tempo presente; permite conhecer a realidade presente e o passado ainda próximo pela experiência e pela voz daqueles que os viveram. Não se resume a uma simples técnica, incluindo também uma postura, na medida em que seu objetivo não se limita à ampliação de conhecimentos e informações, mas visa conhecer a versão dos agentes. Permite conhecer diferentes versões sobre um mesmo período ou fato, versões estas marcadas pela posição social daqueles que os viveram e os narram. (LANG, 2001, p. 96).
}

Thompson (2006, p. 20) ainda enfatiza a história oral como um campo interdisciplinar. "Ela não é simplesmente histórica, mas também sociológica, antropológica, pois ela se baseia nessa forma fundamental de interação humana, que transcende as disciplinas”. Santhiago e Magalhães (2013) ainda ressaltam a metodologia como recurso valioso para variados estudos sobre vidas, sobre grupos sociais e comunidades, sobre o presente. 
Durante a pesquisa foram realizadas entrevistas em cada fazenda parceira do projeto com proprietário/a ou com responsável pela gerência do empreendimento e com o funcionário mais antigo, vivendo na propriedade. No caso das fazendas históricas selecionadas pelo projeto em políticas públicas da PPPP/FAPESP, percebe-se que, de grandes propriedades produtoras de café ou cana, hoje se tornaram, pelo arrendamento de suas terras, propriedades relativamente pequenas (45 a 50 alqueires) com pouca ou nenhuma atividade agrícola. Nota-se uma clara perda de poder econômico de seus proprietários que encaram o turismo cultural e a educação patrimonial como sua fonte principal de renda na atualidade.

Nos trabalhos em campo realizados nas propriedades históricas, fiz uma rápida passagem pelo patrimônio arquitetônico preservado e escolhi um local mais calmo, solicitando ao proprietário que me indicasse o funcionário mais antigo, ainda vivendo no local, para colhermos sua história de vida na fazenda. Assim, realizou-se primeiramente um levantamento do patrimônio imaterial que se apresenta nas dezoito fazendas históricas paulistas, através de entrevistas abertas para a rememoração dos saberes tradicionais rurais com os proprietários e também com os funcionários mais antigos em fazendas que realizam atividades educacionais e turísticas no espaço da propriedade.

Para a entrevista, elaborei previamente um roteiro de questões, tendo por base a história da propriedade, os itens lendas e causos, festas e comemorações, culinária típica da fazenda, atividades musicais, de artesanato e remédios caseiros feitos à base de plantas. Elas permitiram um conhecimento e crítica das atividades de educação patrimonial e de turismo cultural no espaço rural atuais, objetivando principalmente elaborar sugestões e caminhos para melhor implementá-las.

Para as narrativas, Lang (2001) mostra através de suas experiências de pesquisa, que existem vários tipos com características distintas: o depoimento, a história de vida e o relato de vida. No caso da presente pesquisa para o levantamento do patrimônio imaterial das fazendas históricas paulistas, utilizamos o relato de vida que a autora caracteriza como:

\footnotetext{
O relato de vida é uma forma menos ampla e livre que a história de vida, dado que é solicitado ao narrador que aborde de modo mais especial determinados aspectos de sua vida, embora dando a ele total liberdade de exposição; o entrevistado sabe do interesse do pesquisador e direciona o relato para determinados tópicos. (LANG, 2001, p. 96-97).
}

Dessa maneira, geralmente consegui colher um depoimento que alterna rememorações prazerosas do passado com constatações sofridas da pobreza cultural da vida social contemporânea nas propriedades históricas visitadas. Destaca-se a manifestação do prazer que 
esse trabalhador diz encontrar, ao relatar para crianças e adolescentes como era o viver nos espaços que eles hoje vêm conhecer. Os trabalhadores entrevistados muitas vezes também falam da realização que encontram ao liderar os passeios equestres e as cavalgadas, realizados com os hóspedes pelos caminhos e trilhas da fazenda, que ele tão bem conhece. "A história oral contém uma mistura do subjetivo e do objetivo, e parte do interesse está em entender como as experiências do passado são reinterpretadas na memória” (THOMPSON, 2006, p. 32).

Lang, Campos e Demartini (2010) afirmam que o documento não fala por si só e precisa ser analisado com vistas à questão do estudo. O trabalho de História Oral não se esgota na realização, gravação, transcrição e arquivamento da entrevista, dado que se orienta para o estudo de um determinado aspecto da realidade social. $\mathrm{O}$ documento resultante da entrevista deve revelar a interação entre os participantes.

Dessa forma, foi imprescindível a utilização de registros em diário de campo, que para Simson e Giglio (2001) é onde estão registrados todos os aspectos da construção da relação entre entrevistador e os vários entrevistados, as percepções e os insigths que aconteceram durante a longa série de contatos e visitas ao campo.

Segundo Meihy e Holanda (p. 152, 2007), uma das funções do caderno de campo é possibilitar um diálogo frequente e constante em relação ao projeto inicial. Para os autores, o caderno de campo se torna um referencial obrigatório nas finalizações dos trabalhos em que são registrados até os problemas de aceitação das ideias dos entrevistados, bem como toda e qualquer reflexão teórica decorrente de debates sobre aspectos do assunto.

Thompson (2006) relata em seu artigo "Histórias de vida como patrimônio da humanidade" seu trabalho com o caderno de campo para registrar o que notava durante sua pesquisa com comunidades pesqueiras:

Quando estava trabalhando com comunidades pesqueiras na Escócia para meu livro Living the Fishing, eu costumava sentar no bar onde os velhos pescadores estavam, na enseada. Observávamos os barcos chegando e eles me contavam quem estava em cada um deles e também um pouco de suas próprias vidas. Aprende-se muito dessa maneira. (THOMPSON, 2006, p. 22).

Nesse contexto, pesquisadoras do Centro de Estudos Rurais e Urbanos - CERU da Universidade de São Paulo afirmam:

No caderno de campo são anotadas observações do contato e da própria entrevista: o ambiente, a conversação anterior e posterior, novos contatos. Do mesmo modo, é registrada a forma diversa de emoção que cerca a rememoração, como hesitações, silêncios, lapsos, associações, momentos de alegria ou tristeza. Há passagens que o entrevistado narra, mas pede que não sejam gravadas; são anotadas para facilitar o entendimento da entrevista, mas não poderão ser utilizadas, nem disponibilizadas no arquivo. (LANG; CAMPOS; DEMARTINI, 2010, p. 44-45). 
Além dos proprietários das fazendas, foram realizadas entrevistas com quinze pessoas que participaram de atividades turísticas - culturais: cinco deles visitantes da Fazenda Quilombo, sendo dois adultos e três idosos, cinco turistas que foram à Fazenda Santo Antônio da Água Limpa, sendo todos adultos e cinco hóspedes da Fazenda Bela Vista, sendo três adultos e dois idosos. Foram acompanhadas as visitas feitas pela propriedade junto aos turistas para criar uma maior aproximação e ao final foram agendados outros encontros para a realização da entrevista. Ao final desse processo foi efetuado o fichamento temático das entrevistas.

Para a entrevista, elaborei previamente um roteiro de questões, tendo por base o significado da viagem para a elevação da qualidade de vida para os velhos, o gosto de conhecer lugares históricos, sugestões para enriquecer a visita realizada, buscando avaliar também se as visitas às fazendas forneçam oportunidades sedutoras de aprendizagem enfocando questões de educação patrimonial, através do turismo cultural, nas quais o turista deixa de vivenciar uma posição passiva para se tornar um visitante ativo envolvido com a realidade a ser conhecida.

Através dos depoimentos tornaram-se explícitas as características do público participante e das atividades realizadas na Fazenda Quilombo, no município de Limeira - SP. Os grupos que mesclavam adultos e idosos eram compostos por pessoas ativas, na faixa etária entre 20 e 80 anos, um público de vida urbana, em sua maioria constituído por mulheres, de classe média, sendo muitas recém-ascendidas a essa condição social.

A programação da visita à fazenda constitui em um primeiro momento com a palestra proferida pela proprietária Maria José Ribeiro (Zezé) sobre o ciclo do café no Brasil e no estado de São Paulo, focalizando a história do município de Limeira e da Fazenda Quilombo. Em um segundo momento, Zezé leva os visitantes para conhecer a cocheira, o terreiro de café e a antiga tulha da fazenda. O momento de grande entusiasmo durante a visita é o plantio de árvore pelo grupo de turistas que está realizando a visita. Para finalizar o passeio, a proprietária oferece o almoço ou o café da tarde, dependendo do horário da visita.

Na Fazenda Santo Antônio da Água Limpa, no município de Mococa - SP, o público pesquisado foram de adultos e idosos ativos na faixa etária entre 30 e 75 anos, de vida urbana, em sua maioria constituído por mulheres, de classe média.

A família Pereira Lima tem um modo diferenciado e especial de cuidar da propriedade, com grande respeito pela natureza preservando tanto o patrimônio material quanto o imaterial e a paisagem, tudo com muita sensibilidade. No momento da entrevista, em que falava sobre o novo cultivo e respeito com a natureza, seu João Pereira Lima Neto, atual proprietário, se emocionou. Desde 2003 utiliza animais no cafezal (bovinos e equinos) com a finalidade de 
construir um sistema natural de agrossilvicultura, e de transformar a fazenda em uma floresta produtiva, como afirma em seu depoimento.

Com a realização do trabalho de campo na Fazenda Bela Vista, no município de Dourado - SP, constata-se que muitas adaptações e reformas foram realizadas para atender aos usos do turismo que se faz presente na propriedade, mas sempre na tentativa de preservar o que já existia. Os 13 chalés que recebem os turistas eram antigas casas de colônia em que imigrantes italianos e espanhóis moravam para poderem trabalhar na fazenda.

O trabalho de campo foi exaustivo, porém muito produtivo. Os seis dias que permaneci na fazenda me proporcionaram construir uma relação mais próxima, tanto com a filha do proprietário Pedroca, a Tucha, quanto com os turistas. Dessa maneira, as entrevistas com os turistas foram realizadas na própria fazenda, salvo uma entrevista que por indicação da Tucha, realizei na Universidade Estadual de Campinas, já que o depoente faz parte do corpo docente da universidade. Já a entrevista com a Tucha ocorreu no último dia de minha estadia no local, momento em que a proprietária estava tranquila e sem turistas na fazenda.

Ao longo dos três primeiros dias, observei toda a movimentação da fazenda, funcionários e turistas. Reconheci primeiramente que a maioria dos turistas se conhecia e a informalidade do espaço me chamou a atenção. Apesar de a fazenda possuir característica de um hotel-fazenda, o tipo de relação construída com o turista é pessoal com trocas de experiências. A diferença não ocorre pelo nível econômico e sim pela relação construída entre o hospedeiro e o hóspede, o que foi confirmado pela análise das entrevistas realizadas com os turistas.

O público participante das atividades realizadas na Fazenda Bela Vista são adultos e idosos ativos, na faixa etária entre 20 e 75 anos, de vida urbana, constituído em sua maioria por mulheres de alto nível econômico.

Nessa perspectiva, a metodologia da história oral possibilitou, a partir de diversas versões do passado, não só preencher lacunas sobre a história de cada tipo de fazenda selecionada pela pesquisa, mas principalmente perceber as relações sociais dos depoentes construídas ao longo da/das visitas realizadas às propriedades, visando a melhoria da compreensão da realidade rural paulista.

Outro fato importante para a metodologia da História Oral são as categorias que foram construídas posteriormente, cruzando entrevistas com o diário de campo, tendo em vista as questões da presente pesquisa e aquelas que também me deram a conhecer os depoentes deste estudo, de forma mais aprofundada. 
- Origem familiar ligada ao meio rural: viveram parte de suas infâncias no ambiente rural, especificamente em grandes propriedades de cultivo cafeeiro ou outras lavouras do estado de São Paulo. Nesse contexto pude compreender que os idosos da presente pesquisa fazem parte da geração nascida nas primeiras décadas do século XX e contam suas histórias de vida a partir dos fluxos imigratórios, ocorridos principalmente no final do século XIX, responsáveis pela vinda de mão de obra para as fazendas de café na região de São Paulo.

- Imigrantes italianos evidenciam que a tradição familiar era a da vida ligada à terra, sendo de origens humildes, tendo vivido em fazendas no estado de São Paulo, na condição de filhos de colonos.

- Mulheres de vida urbana com interesse na informalidade proporcionada pelo modo de vida rural e preocupadas em transmitir o conhecimento e experiências do meio rural para os filhos.

- É interessante observar finalmente, que mulheres são as responsáveis pela administração das três fazendas pesquisadas, e a maioria dos visitantes/turistas nesses espaços também é do mesmo sexo.

Tais experiências caracterizaram-se por apresentar uma situação entre a vida quotidiana e outras realidades, oferecendo ao visitante uma quantidade e qualidade de informações indisponíveis em seu ambiente natural, tornando possível o turista adquirir um conhecimento da propriedade visitada, compreendendo e respeitando o patrimônio e compartilhando essa experiência com outras pessoas, tanto no momento da visita, como posteriormente.

Lang, Campos e Demartini (2010) reiteram que a História Oral é um processo de construção conjunta entre pesquisador/pesquisado, não havendo receita pronta para a condução de um estudo.

As narrativas orais coletadas no trabalho de História Oral podem assumir formas distintas, mas que no caso das entrevistas com os turistas, utiliza-se o depoimento oral que segundo Lang, Campos e Demartini:

\footnotetext{
O depoimento oral constitui uma modalidade bastante diversa das anteriores, à medida que se busca, através dele, obter informações e o testemunho do entrevistado sobre sua vivência em determinadas situações ou a participação em determinadas instituições que se quer estudar. (LANG; CAMPOS; DEMARTINI, 2010, p. 45).
}

Nesse sentido, é necessário se pensar no turismo como um benefício ao patrimônio cultural e, ao mesmo tempo, levar em conta os perigos de uma atividade turística descontrolada. Nesse caso, o turismo cultural passa a desencadear um processo entre passado e presente, com 
testemunhas vivas, o que foi verificado nessas fazendas históricas, fugindo da ideia dos resorts e da artificialidade que os compõem.

Nessas fazendas os proprietários rurais recebem os hóspedes, levam-nos para conhecer todo o funcionamento do lugar, o modo de vida, hábitos e costumes locais e fazem com que as pessoas entrem em contato, interagindo com o meio, seja através de passeios à cavalo, de caminhadas ou da participação nas atividades de plantio e colheita - atividades agrícolas. Um diferencial marcante é que os turistas são acomodados como amigos e vivenciam a experiência como se fizessem parte da família. (FAUSTINO, 2006, p. 23).

Cabral (2004) nos chama a atenção para que o patrimônio é um campo extraordinário onde as pessoas podem vivenciar uma série de experiências, sendo concebido como "campo de educação". A autora ainda ressalta que, para preservar o patrimônio, é preciso antes de tudo conhecê-lo, e é por isso que o patrimônio é campo de educação, ou seja, é necessário entender a educação como uma prática para a cidadania, compreendendo-a como a garantia de acesso aos conhecimentos produzidos historicamente pela humanidade e, simultaneamente, como formadora de indivíduos críticos, criativos e autônomos, capazes de agir no seu meio e transformá-lo. Cabral (2004) finaliza afirmando que os indivíduos devem ser atores de seu próprio desenvolvimento, partindo daí a discussão do patrimônio a par com a questão do poder e das significações.

Dessa forma, a meta da interpretação sociocultural desse rico patrimônio rural paulista aplicada à atividade turística é estabelecer uma rede de descobertas para o visitante, seja ele proveniente das classes média ou média-alta ou ainda originário das classes populares, estimulando o seu olhar, provocando a sua curiosidade e levando-o a descobrir muito mais sobre o lugar e seus habitantes.

Nesse sentido, a história do tempo presente desses locais, referindo-se ao espaço-tempo de proximidade com os sujeitos viventes, com suas lendas, causos e modinhas, passa a valorizar tanto as atrações naturais como as culturais, ainda preservadas nas fazendas históricas paulistas.

\section{CONSIDERAÇÕES FINAIS}

Observo que os visitantes/dia ou excursionistas e os turistas que se hospedam nas propriedades têm buscado tais atividades no sentido de vivenciarem concretamente experiências que os remetam às histórias e memórias difundidas no âmbito familiar, referentes aos avós ou bisavós que emigraram para o Brasil para trabalhar como colonos em fazendas cafeeiras. 
Estas propriedades apresentavam grande produção e obtinham muito lucro no final do século XIX e primeiras décadas do XX, exigindo para isso constante ampliação da mão de obra envolvida na produção cafeeira. Esse imaginário circulante no âmago das famílias originárias da população migrante encontra uma espécie de concretização nas visitas a tais propriedades que se voltam para as atividades turísticas e por isso recebem adultos e idosos que buscam entender, no concreto, suas histórias familiares para poder repassá-las com segurança às novas gerações.

Gastronomia, modo de vida rural, memória e história das propriedades rurais são fatores aglutinadores que constituem um instrumento de ativação do imaginário individual e coletivo dos turistas que visitam as fazendas selecionadas pela pesquisa.

Hoje, com o intenso processo de urbanização e avanço do agronegócio tais propriedades estão em risco de extinção. Dessa forma, a pesquisa possibilitou através da metodologia da história oral, a construção de um conhecimento sobre a cultura material e imaterial e sua utilização em atividades de turismo cultural em espaços rurais privados (as fazendas históricas), anteriormente inacessíveis aos pesquisadores das diferentes disciplinas que integraram a equipe da pesquisa em políticas públicas FAPESP - CMU.

Além disso, trouxe novas contribuições através de encontros e discussões que envolvem diretamente os proprietários das fazendas históricas, em que a atividade turística passa a representar uma melhoria da qualidade de vida dos visitantes urbanos. Tem-se o aumento das potencialidades de entendimento via relações intergeracionais e o desenvolvimento do sentido de pertencimento, conduzindo à construção da cidadania e à ampliação do conceito de patrimônio cultural através da preservação do patrimônio material e imaterial.

A educação patrimonial é considerada uma questão difícil e atual, considerando a tendência cultural hoje dominante de crise de memória. Nessa perspectiva, a metodologia da história oral possibilitou a preservação da memória e do patrimônio cultural, servindo como um exercício de educação patrimonial, como forma de sensibilizar os visitantes para o compromisso com a memória, com a história e com as próprias ações vivenciadas cotidianamente na construção da história individual, coletiva e também do tempo presente.

A Educação Patrimonial voltada para o público idoso esclarece e fundamenta o trabalho de conhecimento, apropriação e valorização de diferentes culturas, em diversos lugares e épocas. Embora fiquem nítidas, as diferenças socioeconômicas e culturais entre os diversos grupos observados, a visita à fazenda parece representar para todos eles um momento de prazer, adquirindo significado de extrema importância para o velho, porque pode representar a fuga da 
rotina e do isolamento ou até a concretização de um sonho, que pela ruptura do cotidiano amplia horizontes históricos e possibilidades de convivência social.

É necessário se pensar a educação patrimonial não só como um aspecto a ser trabalhado comumente em escolas, mas também em espaços educacionais não formais, como é o caso das fazendas históricas selecionadas nesta pesquisa, e como fonte de ativação da memória social. Mediante a pesquisa de campo realizada e através da análise de depoimentos, propôs-se mostrar a intersecção da memória com a vida social e o tempo presente.

A pesquisa finalmente constatou, em situação de visita às fazendas recebendo públicos idosos, o prazer de construir um conhecimento sobre o passado rural que também poderia ser um passado de outras gerações da família, sem restrições curriculares, sem cobranças avaliativas e envolvendo memórias orais partilhadas por várias gerações.

Observa-se que o turismo cultural no espaço rural parte da constatação de que se devem prover atividades turístico-culturais com infraestrutura e facilidades instaladas em propriedades, tanto aquelas de pequenos produtores rurais, como neste caso nas fazendas históricas paulistas selecionadas. Estas são motivadoras e propiciadoras de trabalho para as famílias residentes no campo e geradoras de oportunidades de emprego, enquanto oferecem aos turistas situações originais para desfrutarem do ambiente rural, vivenciando atividades e costumes ausentes do ambiente urbano.

Assim, as experiências das visitas acompanhadas durante o trabalho de campo demonstraram que a conservação do patrimônio cultural rural pode ser entendida, sobretudo, como uma consequência do turismo cultural e da educação patrimonial não formal. Sendo assim, a atividade turística contribuiu no sentido da valorização da cultura rural como um todo, através do patrimônio material (patrimônio arquitetônico) e do imaterial (saberes e fazeres).

As possibilidades de um trabalho de Educação Patrimonial não formal em fazendas históricas paulistas promovem a ativação da memória social, construindo a autoestima principalmente dos idosos, de modo a se identificarem com o patrimônio e o valorizarem como um bem de toda a coletividade.

A pesquisa sobre o Patrimônio Cultural Rural Paulista, por meio da metodologia da história oral, se torna um trabalho sobre a utilização dos bens culturais como fonte de educação, lazer e turismo, possibilitando um exercício de sensibilização para a valorização dos espaços rurais no tempo presente, a partir da análise das representações dos sujeitos e seus papéis, o imaginário rural, e da decodificação dos valores existentes naquele espaço. 


\section{REFERÊNCIAS}

ALMEIDA, Maria. Prefácio. In: PAES, Maria Teresa Duarte; OLIVEIRA, Melissa Ramos da Silva (orgs). Geografia, Turismo e Patrimônio Cultural. São Paulo: Annablume, 2010.

BARRETTO, Margatita. Turismo e Identidade Local: Uma visão antropológica. Campinas, (SP): Papirus; 2001.

BORTOLUCCI, Maria Angela. Prefácio. In: CORREIA, Telma; BORTOLUCCI, Maria Angela. Lugares de produção: arquitetura, paisagens e patrimônio. São Paulo: Annablume, 2013.

CABRAL, Magaly. Memória, patrimônio e educação. Resgate: Revista de Cultura, Campinas (SP): Centro de Memória UNICAMP, n. 13, p. 35-42, 2004.

DAVIS, K. Biography as critical methodology. Newsletter Research Committee of ISA, n. 38, Utrecht University, 2003.

DEBERT, Guita. A construção e a reconstrução da velhice: família, classe social e etnicidade. In: NERI, Anita; DEBERT, Guita. (orgs.). Velhice e sociedade. Campinas (SP): Papirus, 1999.

FAUSTINO, Ricardo. O turismo em espaço rural como modo de valorização do Patrimônio Cultural: estudos de caso na média depressão periférica paulista: o caso das Fazendas Capoava e Ibicaba. 2006. 148 f. Tese (Doutorado) - Programa de Pós-Graduação em Geografia, Faculdade de Filosofia, Letras e Ciências Humanas, Universidade de São Paulo/ USP, São Paulo, SP.

FERNANDES, Renata. A cidade educativa como espaço de educação não formal, as crianças e os jovens como indicadores ambientais. Paisagens em debata. Revista eletrônica da área Paisagem e Ambiente. FAU/USP, n. 05, dez. 2007.

GRAZIANO, Andre. A paisagem educativa um estudo comparativo sobre a paisagem no contexto do patrimônio cultural rural paulista. 2016. 392 f. Tese (Doutorado) - Programa de Pós-Graduação em Educação, Faculdade de Educação, Universidade Estadual de Campinas/UNICAMP, Campinas, SP.

HALBWACHS, Maurice. A memória coletiva. São Paulo (SP): Vértice; 1990.

LANG, Beatriz Gordo (org). História Oral: procedimentos e possibilidades. Desafios da pesquisa em Ciências Sociais, São Paulo, CERU, Texto 8, série 2, p. 91-112, 2001.

LANG, Beatriz Gordo; CAMPOS, Maria Cristina; DEMARTINI, Zeila. História Oral, Sociologia e Pesquisa: a abordagem do CERU. São Paulo: Humanitas, 2010.

LIMA, Lívia Morais Garcia. Turismo, Cultura e Velhice Bem-Sucedida: contribuições para a elaboração de atividades turístico-culturais para idosos no contexto de fazendas históricas paulistas. 2010. 97 f. Dissertação (Mestrado) - Programa de Pós-Graduação em Gerontologia, 
Faculdade de Ciências Médicas, Universidade Estadual de Campinas/UNICAMP, Campinas, SP.

MARINS, Paulo. Preservação do patrimônio rural no Estado de São Paulo: entre ação governamental e práticas sociais. In: CORREIA, Tania; BORTOLUCCI, Maria Angela. (orgs). Lugares de produção: arquitetura, paisagens e patrimônio. São Paulo: Annablume, 2013.

MEIHY, José; HOLANDA, Fabíola. História Oral: como fazer, como pensar. São Paulo: Contexto, 2007.

OLIVEIRA, Gláucia. Gestão e vivências de velhices nas Repúblicas de Idosos de Santos. 2009. 153 f. Dissertação (Mestrado) - Programa de Pós-Graduação em Antropologia, Faculdade de Filosofia, Letras e Ciências Humanas, Universidade de São Paulo/USP, São Paulo, SP.

PORTELLI, Alessandro. O que faz a história oral diferente. Projeto História: Revista do Programa de Estudos Pós-Graduados em História e do Departamento de História da PUC-SP, Pontifícia Universidade Católica de São Paulo, São Paulo, 1997.

SANTHIAGO, Ricardo; MAGALHÃES, Valéria. Depois da utopia: a história oral em seu tempo. São Paulo: Letra e Voz: FAPESP, 2013.

SILVA, Luis. A procura do turismo em espaço rural. Revista Etnográfia, 11 (1), p. 141-163, 2007.

SIMSON, Olga Rodrigues de Moraes von; PARK, Margareth B.; FERNANDES, Renata Sieiro. Educação não formal: Cenários da criação. Campinas (SP): Editora da UNICAMP/Centro de Memória; 2001.

SIMSON, Olga Rodrigues de Moraes von; GIGLIO, Zélia. A arte de recriar o passado: história oral e velhice bem-sucedida. In: NERI A. L. (org). Desenvolvimento e Envelhecimento: Perspectivas Biológicas, Psicológicas, Sociológicas. Campinas (SP): Papirus; 2001.

TOGNON, Marcos. Patrimônio: entre passado e presente. In: PARK, Margareth B. (org.). Formação de Educadores: memória, patrimônio e meio ambiente. Campinas, SP: Mercado de Letras, 2003.

TOGNON, Marcos. Patrimônio Cultural Rural Paulista: espaço para pesquisa, educação e turismo (oitava chamada para o Programa de Pesquisas em Políticas Públicas da FAPESP PPPP/2007). Cidade Universitária Zeferino Vaz, Campinas, SP: Centro de Memória UNICAMP, 2007.

THOMPSON, Paul. Histórias de Vida como Patrimônio da Humanidade. In: História Falada: memória, rede e mudança social. SESC SP: Museu da Pessoa: Imprensa Oficial do Estado de São Paulo, 2006.

Recebido em: 14 de setembro de 2018

Aceito em: 21 de dezembro de 2018 